\title{
Perceptual processing advantages for trauma-related visual cues in post-traumatic stress disorder
}

\author{
B. Kleim, T. Ehring and A. Ehlers* \\ Department of Psychology, Institute of Psychiatry, King's College London, UK
}

Background. Intrusive re-experiencing in post-traumatic stress disorder (PTSD) comprises distressing sensory impressions from the trauma that seem to occur 'out of the blue'. A key question is how intrusions are triggered. One possibility is that PTSD is characterized by a processing advantage for stimuli that resemble those that accompanied the trauma, which would lead to increased detection of such cues in the environment.

Method. We used a blurred picture identification task in a cross-sectional $(n=99)$ and a prospective study $(n=221)$ of trauma survivors.

Results. Participants with acute stress disorder (ASD) or PTSD, but not trauma survivors without these disorders, identified trauma-related pictures, but not general threat pictures, better than neutral pictures. There were no group differences in the rate of trauma-related answers to other picture categories. The relative processing advantage for trauma-related pictures correlated with re-experiencing and dissociation, and predicted PTSD at follow-up.

Conclusions. A perceptual processing bias for trauma-related stimuli may contribute to the involuntary triggering of intrusive trauma memories in PTSD.

Received 26 November 2010; Revised 17 May 2011; Accepted 20 May 2011; First published online 21 June 2011

Key words: Acute stress disorder, dissociation, intrusive memories, perception, post-traumatic stress disorder, priming.

\section{Introduction}

Some trauma survivors are haunted by unwanted distressing memories for years. These commonly take the form of vivid and distressing sensory impressions from the trauma that suddenly pop into one's mind and seem to come 'out of the blue'. The sensations are predominantly visual and subjectively seem to happen in the 'here and now' rather than being memories of past events (Ehlers et al. 2002; Michael et al. 2005a). Such intrusive re-experiencing is a core symptom of post-traumatic stress disorder (PTSD). For example, a motor vehicle accident (MVA) survivor may re-experience the sight of headlights coming towards them, just like before the crash, or an assault survivor may re-experience a glimpse of the assailant standing before them with a knife, just like during the assault.

Clinical observations suggest that a wide range of stimuli trigger re-experiencing (e.g. Foa et al. 1989; Brewin et al. 1996). However, key questions remain regarding how and why re-experiencing is so easily

* Address for correspondence: Professor A. Ehlers, Department of Psychology (PO77), Institute of Psychiatry, King's College London,

De Crespigny Park, London SE5 8AF, UK.

(Email : anke.ehlers@kcl.ac.uk) triggered in PTSD. Interview and questionnaire studies have suggested that triggers are often perceptually similar to the intrusive content or to stimuli that signalled the onset of these moments (Ehlers et al. 2004; Michael et al. 2005a). This raises the possibility that people with PTSD may preferentially process perceptual cues that are similar to those encountered during trauma. Such a processing advantage would have the consequence that trauma-related stimuli are more readily noticed than other stimuli in the environment, and may then trigger intrusive trauma memories through unintentional, cue-driven memory retrieval (Ehlers \& Clark, 2000; Brewin et al. 1996, 2010).

Two lines of work in cognitive psychology suggest that such a perceptual processing advantage for trauma-related cues may develop after trauma. First, people with anxiety disorders show selective attention to threat cues. This cognitive bias selectively favours the detection and processing of threat material (e.g. Foa et al. 1991; Thrasher et al. 1994). It is generally thought to be driven by a pre-attentive analysis of whether or not a stimulus is threat related, followed by an automatic shift of attention to the location of threatening stimuli (Öhman, 1993; Öhman \& Soares, 1993), although strategic allocation of attention such as

The online version of this article is published within an Open Access environment subject to the conditions of the Creative Commons Attribution-NonCommercial-ShareAlike licence <http://creativecommons.org/licenses/by-nc-sa/2.5/>. The written permission of Cambridge University Press must be obtained for commercial re-use. 
scanning for danger may also play a role. There is some evidence that attentional bias to threat plays a role in PTSD. In several studies using experimental paradigms, such as the emotional Stroop test or dotprobe paradigm, survivors with PTSD showed an attentional bias towards trauma-related stimuli (e.g. Foa et al. 1991; Bryant \& Harvey, 1995; Moradi et al. 1999; Vythilingam et al. 2007; for reviews see Buckley et al. 2000; Constans, 2005). The majority of these studies investigated responses to trauma-related words (e.g. ' rape', 'bodybag') and thus did not capture the perceptual nature of stimuli that typically trigger intrusive memories. As intrusive trauma memories and their triggers seem to be primarily visual (Ehlers et al. 2002), studies of perceptual processing of visual stimuli in PTSD are needed.

Second, there is some evidence that perceptual priming plays a role in PTSD. Perceptual priming refers to a form of implicit memory that is characterized by facilitated perception of a stimulus as the result of previous exposure to this stimulus (e.g. Schacter, 1992). It has been suggested that stimuli that were temporally associated with trauma are strongly primed in people with PTSD, hence leading to a reduced perceptual threshold for these stimuli (Ehlers \& Clark, 2000). Studies with healthy volunteers suggest that perceptual priming may facilitate re-experiencing. Several studies found that stimuli that occurred in a traumatic context are more strongly primed than those occurring in a neutral context. Visual stimuli were embedded in traumatic and neutral picture stories, and perceptual priming was assessed later with a picture identification task (Arntz et al. 2005; Ehlers et al. 2006a; Michael \& Ehlers, 2007). The degree of priming for objects from the trauma stories indeed predicted subsequent intrusive re-experiencing (Ehlers et al. 2006a ; Michael \& Ehlers, 2007).

Several clinical studies further found that stimuli associated with the trauma can be more strongly primed post-trauma in people with PTSD than in those without PTSD. Participants encoded traumarelated and control stimuli, and priming was tested later with word-stem completion or perceptual identification tasks. The results mostly support the hypothesis of greater perceptual priming for material associated with the trauma in people with PTSD compared to those without PTSD (Amir et al. 1996; Michael et al. 2005b; Ehring \& Ehlers, 2011; but see McNally \& Amir, 1996, for negative findings). Amir et al. (2010) used picture clarity ratings as a measure of implicit memory for previously encoded traumarelated, negative and neutral pictures. Trauma survivors with PTSD showed a greater implicit memory bias for trauma and negative pictures relative to neutral pictures than those without PTSD.
The present two studies tested the hypothesis that, after trauma, a relative processing advantage for trauma-related perceptual stimuli compared to neutral stimuli in the environment (processing advantage for trauma-related cues, PAT) contributes to intrusive re-experiencing, and thus the development of PTSD. We expected that trauma survivors with PTSD or acute stress disorder (ASD, a precursor of PTSD in the first month post-trauma) show a processing advantage for trauma-related material compared to neutral material. Trauma survivors were asked to identify blurred, not easily recognizable pictures that resembled stimuli they were likely to have encountered during their trauma, along with blurred neutral pictures. If PAT is a risk factor for PTSD, then trauma survivors with ASD/PTSD should display such a processing advantage for trauma-related perceptual stimuli and should be better at identifying blurred trauma-related pictures than blurred neutral pictures, whereas trauma survivors without ASD/ PTSD would not be expected to show differences in identification rates (Hypothesis 1). Blurred pictures of general threatening content unrelated to the trauma were included to test the specificity of the hypothesized processing advantage. We further expected that a processing advantage for trauma-related material would be associated with intrusive trauma memories, with the subjective experience that these appear 'out of the blue', and other re-experiencing symptoms including dissociative reactions (Hypothesis 2). We also predicted that PAT would be associated with fear and perceptual processing during the trauma (Hypothesis 3), and that it would predict chronic PTSD (Hypothesis 4).

\section{Method \\ Participants}

Participants were trauma survivors who had been treated for their injuries in an Emergency Department in South London, UK, following an MVA or assault. Study 1 is a cross-sectional study of 99 MVA survivors who were assessed between 3 and 12 months after the accident (see Ehring et al. 2006, for details). As shown in Table 1, $22(22.0 \%)$ of the participants met diagnostic criteria for PTSD. Study 2 is a prospective study that assessed assault survivors at 2 weeks $(n=221)$ and 6 months $(n=202)$ after the trauma (see Kleim et al. 2007, for details). At 2 weeks, 37 participants (16.7\%) met diagnostic criteria for ASD, and at 6 months, 46 $(22.7 \%)$ met criteria for PTSD. Table 1 shows sample characteristics.

Participants first received an information sheet about the study in the mail and were then invited by 
Table 1. Sample characteristics for Studies 1 and 2

\begin{tabular}{|c|c|c|c|c|c|c|}
\hline \multirow[b]{2}{*}{ Variable } & \multicolumn{3}{|c|}{ Study 1 : Cross-sectional MVA } & \multicolumn{3}{|c|}{ Study 2: Prospective assault } \\
\hline & $\begin{array}{l}\text { PTSD } \\
(n=22)\end{array}$ & $\begin{array}{l}\text { No PTSD } \\
(n=77)\end{array}$ & $\begin{array}{l}\text { Statistical } \\
\text { significance } \\
\chi^{2} \text { or } F, p\end{array}$ & $\begin{array}{l}\text { ASD } \\
(n=36)\end{array}$ & $\begin{array}{l}\text { No ASD } \\
(n=185)\end{array}$ & $\begin{array}{l}\text { Statistical } \\
\text { significance } \\
\chi^{2} \text { or } F, p\end{array}$ \\
\hline Sex; proportion male, $n(\%)$ & $11(50)$ & $44(57)$ & $0.47,0.63$ & $18(50)$ & $130(82)$ & $5.0,0.03$ \\
\hline $\begin{array}{l}\text { Ethnicity; proportion Caucasian, } \\
n(\%)\end{array}$ & $15(68)$ & $60(78)$ & $1.01,0.40$ & $19(53)$ & $107(58)$ & $2.86,0.24$ \\
\hline Socio-economic status ${ }^{\mathrm{a}}, n(\%)$ & & & $8.14,0.09$ & & & $10.05,0.02$ \\
\hline Very low income $(<£ 10000)$ & $9(41)$ & $15(21)$ & & $21(58)$ & $74(40)$ & \\
\hline Low income $(£ 10000-£ 20000)$ & $6(27)$ & $14(19)$ & & $6(17)$ & $42(23)$ & \\
\hline $\begin{array}{l}\text { Moderate/high income } \\
(£ 20000-£ 40000)\end{array}$ & $7(32)$ & $44(61)$ & & $4(11)$ & $59(32)$ & \\
\hline Refused information & $0(0)$ & $4(4)$ & & $5(14)$ & $10(5)$ & \\
\hline Marital status, $n(\%)$ & & & $1.54,0.46$ & & & $4.0,0.41$ \\
\hline Single & $15(68)$ & $42(55)$ & & $25(70)$ & $121(65)$ & \\
\hline Married & $6(27)$ & $24(32)$ & & $4(11)$ & $37(20)$ & \\
\hline Divorced/separated & $1(5)$ & $10(13)$ & & $7(19)$ & $21(11)$ & \\
\hline Refused information & $0(0)$ & $1(0)$ & & $0(0)$ & $6(3)$ & \\
\hline Education, $n(\%)$ & & & $4.84,0.18$ & & & $7.79,0.10$ \\
\hline No examinations & $4(18)$ & $5(7)$ & & $11(31)$ & $35(19)$ & \\
\hline A-Level ${ }^{\mathrm{b}} / \mathrm{O}$-Levels ${ }^{\mathrm{c}}$ & $6(28)$ & $28(36)$ & & $16(44)$ & $67(36)$ & \\
\hline Bachelor/postgraduate degree & $7(32)$ & $35(46)$ & & $6(17)$ & $59(32)$ & \\
\hline Other & $5(23)$ & $8(11)$ & & $3(8)$ & $24(13)$ & \\
\hline Employment status, $n(\%)$ & & & $2.08,0.23$ & & & $15.49,<0.001$ \\
\hline Employed/studying & $15(68)$ & $63(82)$ & & $16(44)$ & $134(72)$ & \\
\hline Unemployed/retired & $7(32)$ & $14(18)$ & & $20(56)$ & $51(28)$ & \\
\hline Age (years), mean (s.D.) & $37.41(14.52)$ & $34.39(9.30)$ & $1.52,0.22$ & $38.7(12.37)$ & $33.60(11.09)$ & $5.62,0.019$ \\
\hline PTSD symptom severity, mean (s.D.) & $26.50(8.99)$ & $8.32(8.09)$ & $84.34,<0.001$ & $34.47(9.46)$ & $16.52(10.10)$ & $83.79,<0.001$ \\
\hline
\end{tabular}

MVA, Motor vehicle accident; PTSD, post-traumatic stress disorder; ASD, acute stress disorder; S.D., standard deviation.

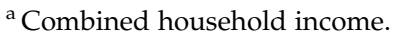

${ }^{\mathrm{b}}$ Equivalent to 13 years of education.

${ }^{\mathrm{c}}$ Equivalent to 11 years of education.

telephone to take part. Written informed consent was obtained at the beginning of the research session after the experimenter had given a complete description of the study and answered all questions. Participants were reimbursed with $£ 30$ (Study 1) or $£ 50$ (Study 2) for their time and travel expenses.

\section{Picture identification task}

This task was developed for the purposes of this study. Participants saw blurred pictures on a computer screen and were asked to name the main object, person or situation shown in the picture. The stimuli were either trauma-related, general threat-related or neutral pictures.

\section{Stimulus material}

Pictures were approximately $9 \mathrm{~cm} \times 12 \mathrm{~cm}$ in size and had been blurred using a Gaussian filter (Adobe Photoshop 3.0). The MVA version of the task (Study 1) comprised two subcategories of nine trauma-related pictures, namely traffic-related (e.g. traffic lights, speedometer) and accident-related pictures (e.g. airbag, police car), and also nine general threat pictures and nine neutral pictures. For the assault version of the task, there were 10 assault-related pictures (e.g. knife, fist, gun), 10 general threat pictures and 10 neutral pictures. Table 2 lists the picture content for both versions.

To adjust the degree of blurring, a series of pilot studies was conducted for each version with volunteers who had never been involved in an MVA/ assault. Each picture was blurred to the level where approximately $50 \%$ of volunteers correctly identified the picture. Mean identification rates were identical for all categories in the pilot samples (MVA task: mean $=0.47$ for all categories, s.D. $=0.15-0.26$; assault task: mean $=0.47$ for all categories, S.D. $=0.19-0.22$ ) and paired $t$ tests of mean identification rates were all non-significant (all $p>0.96$ ). 
Table 2. Pictures used in motor vehicle accident (MVA) and assault versions of the blurred picture task

\begin{tabular}{|c|c|c|c|c|}
\hline & \multicolumn{2}{|l|}{ Trauma-related } & \multirow[b]{2}{*}{ General threat } & \multirow[b]{2}{*}{ Neutral } \\
\hline & Accident & Traffic & & \\
\hline \multicolumn{5}{|l|}{ Study 1} \\
\hline & Airbag & Bollard & Cemetery & Letter box \\
\hline & Ambulance & Cars at night & Aggressive dog & Cup \\
\hline & Broken window & Motorbike helmet & Gun & Door handle \\
\hline & Crashed car & Rear light of car & Injection & Dustbin \\
\hline & Crash test dummy & Road marking & Explosion & Fork \\
\hline & Front of a car & Seat belt & Sinking ship & Coat hangers \\
\hline & Neck brace & Speedometer & Skulls & Iron \\
\hline & Police car & Traffic lights & Snake & Razor \\
\hline & Stretcher & Traffic jam & Spider & Desk fan \\
\hline \multicolumn{5}{|l|}{ Study 2} \\
\hline & Abduction with knife & & Crashed car & Letter box \\
\hline & Baseball bat & & Junkie & Door handle \\
\hline & Knife & & Dog & Hair dryer \\
\hline & Bloody hands & & Earthquake $^{\mathrm{a}}$ & Dustbin \\
\hline & Dark alley & & Grey shark & Chair \\
\hline & Eyes $^{\mathrm{a}}$ & & Sinking ship & Iron \\
\hline & Fist & & Skulls & Toilet paper \\
\hline & Gang & & Spider & Toaster \\
\hline & Man in hooded shirt & & Volcano & Towel $^{\mathrm{a}}$ \\
\hline & Masked man & & War scene & Pepper jar \\
\hline
\end{tabular}

${ }^{a}$ Identification rates for these pictures were constantly at floor or at ceiling and they were excluded from the analyses.

\section{Task procedure}

Blurred pictures were presented on a computer screen in random order. Each picture was preceded by a fixation cross. Participants were asked to name the main object or situation as quickly as possible. Participants saw two practice pictures (horse, hamburger) to ensure that the instructions were clear. In Study 1, pictures were terminated when participants pressed a key indicating they were ready to respond. In Study 2, pictures disappeared automatically with voice onset. Answers were tape-recorded to allow exact scoring after the session.

\section{Measures of PTSD symptoms and cognitive processing}

Diagnoses

Post-traumatic diagnoses were assessed with standardized structured clinical interviews by two trained master-level psychologists. In Study 1, PTSD diagnoses were established with the Structured Clinical Interview for DSM-IV (SCID; First et al. 1996). In Study 2, participants were interviewed with the Acute Stress Disorder Scale (Bryant \& Harvey, 2000) at 2 weeks after the assault to assess ASD. At the 6-month follow-up, the same interviewer conducted the SCID over the telephone to assess PTSD. Inter-rater reliability was high $(\kappa=0.97$ for ASD, $\kappa=0.82$ for PTSD; based on $n=56$ interviews, two trained raters who were blind to each others' ratings).

\section{PTSD symptom severity}

The Posttraumatic Stress Diagnostic Scale (PDS; Foa et al. 1997) is a standardized and validated self-report measure of PTSD symptom severity that has been widely used with clinical and non-clinical samples of traumatized individuals. The PDS asks participants to rate 17 items regarding how much they were bothered by each of the PTSD symptoms specified in DSM-IV ranging from 0 (never) to 3 (five times a week or more/very severely). The first five items correspond to re-experiencing symptoms.

\section{Intrusive trauma memories}

The presence of intrusive trauma memories in the past week was assessed using the Intrusion Interview, a semi-structured interview that covers intrusion frequency, modality and distress (Michael et al. 2005a). Intrusive memories were scored as present if participants reported unintentional memories of aspects of the trauma with a distress rating of at least 60 . 


\section{'Out of the blue' memories}

The item 'I am reminded of the accident/assault for no apparent reason' from the Trauma Memory Questionnaire (Halligan et al. 2003) was used to assess whether participants perceived intrusive memories as occurring 'out of the blue'.

\section{Dissocation}

The State Dissociation Questionnaire (SDQ; Murray et al. 2002) assessed ongoing dissociation, a common feature of chronic PTSD. The nine-item SDQ assesses different aspects of dissociation such as derealization, depersonalization, detachment, altered time sense, emotional numbing, and reduction of awareness in surroundings. It has been shown to be reliable and to predict PTSD after trauma (Murray et al. 2002; Halligan et al. 2003). Internal consistencies in the present samples were $\alpha=0.90$ and $\alpha=0.95$ respectively.

Fear and data-driven processing during trauma

In Study 2, participants completed the Peritraumatic Fear Scale to assess the degree of fear during the trauma (Halligan et al. 2003). Participants rated the degree to which they felt a list of emotions during the trauma (e.g. fearful, terrified), each on a scale from 0 (not at all) to 4 (very strongly), $\alpha=0.90$. The Datadriven Processing Scale (Halligan et al. 2003) assesses the extent to which participants engaged primarily in perceptual processing during the assault (e.g. 'It was just a stream of unconnected impressions following each other'). The scale has been shown to have good internal consistency and validity (Halligan et al. 2002, 2003). Internal consistency was $\alpha=0.86$.

\section{Data analyses}

The main dependent variable was the proportion of correctly identified pictures in the blurred picture task. To check for a possible response bias towards giving trauma-related answers regardless of picture content, we determined how many of the incorrect answers in response to general threat and neutral pictures were trauma related (false alarms). Mixed design ANOVAs with picture type (trauma, general threat, neutral) as the within-subject variable and diagnostic group (Study 1: PTSD versus No-PTSD; Study 2; ASD versus No-ASD) as the between-group variable tested differences in identification rates between diagnostic groups. In line with Hypothesis 1, we expected a significant interaction between diagnostic group and picture type.
In Study 1, preliminary analyses showed that there were no differences in identification rates for accident and traffic pictures $[F(1,97)=0.00, p=0.95]$, and no interaction between subcategory and group $[F(1,97)=$ $0.24, p=0.63]$. Thus, the main analyses in Study 1 were carried out by combining both sets of trauma-related pictures.

The relative processing advantage for traumarelated stimuli (PAT) was defined as the difference score: the identification rate for trauma-related pictures minus the identification rate for neutral pictures. The expected associations (Hypothesis 2) of PAT with intrusive memories and features of PTSD were assessed with point-biserial correlations (for dichotomous measures) or Pearson correlation (for continuous measures). PDS and SDQ scores were square-root transformed to normalize distributions. In Study 2, Pearson correlations tested correlations with responses during the trauma (Hypothesis 3), and a logistic regression analysis tested whether PAT predicts later PTSD diagnosis (Hypothesis 4). $\alpha$ was set at 0.05 .

\section{Results}

\section{Study 1: Cross-sectional study of MVA survivors}

Overall identification rates and test of response bias

Mean picture identification rates across diagnostic groups were in a similar range as in the pilot study (mean $=0.50$, s.D. $=0.20$ for traffic pictures, mean $=$ 0.51 , S.D. $=0.22$ for accident-related pictures, mean $=$ 0.50 , S.D. $=0.20$ for general threat pictures, and mean $=0.47$, S.D. $=0.19$ for neutral pictures). An ANOVA showed that there were no differences in response bias between the PTSD and No-PTSD groups for traffic- and accident-related answers in response to general threat and neutral pictures $[F(1,97)=2.04$, $p=0.156$ for traffic-related answers; $F(1,97)=0.28$, $p=0.596$ for accident-related answers].

\section{Group differences (Hypothesis 1)}

The results for the picture identification task are displayed in Table 3. A 2 (diagnostic group: PTSD, No-PTSD) $\times 3$ [picture type: trauma-related (accident or traffic), general threat, neutral] ANOVA showed no significant main effect of diagnostic group $[F(1,97)=0.002, p=0.967]$ but a significant main effect of picture type $[F(2,194)=3.53, p=0.031]$, and the expected interaction between diagnostic group and picture type $[F(2,194)=3.08, p=0.048]$. Separate follow-up analyses for each diagnostic group showed, as expected, a significant effect of picture type for the PTSD group $[F(2,42)=6.20, p=0.004]$ but not for the 
Table 3. Mean (S.D.) picture identification rates for participants with and without post-traumatic stress disorder (PTSD, Study 1) and acute stress disorder (ASD, Study 2)

\begin{tabular}{|c|c|c|c|c|}
\hline & $\begin{array}{l}\text { Trauma-related } \\
\text { pictures }\end{array}$ & $\begin{array}{l}\text { General } \\
\text { threat } \\
\text { pictures }\end{array}$ & $\begin{array}{l}\text { Neutral } \\
\text { pictures }\end{array}$ & $\begin{array}{l}\text { Relative processing advantage } \\
\text { for trauma-related pictures }\end{array}$ \\
\hline Study 1 & Accident or Traffic & & & Accident or Traffic \\
\hline $\operatorname{PTSD}(n=22)$ & $0.55(0.21)$ & $0.47(0.17)$ & $0.42(0.17)$ & $0.12(0.15)$ \\
\hline No PTSD $(n=77)$ & $0.49(0.16)$ & $0.48(0.23)$ & $0.49(0.19)$ & $0.00(0.19)$ \\
\hline Study 2 & Assault & & & Assault \\
\hline $\operatorname{ASD}(n=36)$ & $0.35(0.18)$ & $0.28(0.14)$ & $0.22(0.19)$ & $0.13(0.20)$ \\
\hline No $\operatorname{ASD}(n=185)$ & $0.36(0.21)$ & $0.32(0.20)$ & $0.34(0.22)$ & $0.02(024)$ \\
\hline
\end{tabular}

S.D., Standard deviation.

No-PTSD group $[F(2,152)=0.16, p=0.851]$. The PTSD group identified more trauma-related pictures than neutral pictures $[F(1,21)=14.52, p<0.001]$. They showed intermediate identification rates for general threat pictures, which did not differ significantly from those for trauma-related $[F(1,21)=3.39, p=0.080]$ and neutral pictures $[F(1,21)=2.30, p=0.144]$.

Correlations of PAT with intrusive memories and features of PTSD (Hypothesis 2)

As expected, PAT correlated with the presence of intrusive memories in the past week [point-biserial correlation $\left(r_{\text {pbis }}\right)=0.21$ ], with the participants' reports that these appeared 'out of the blue' $(r=0.28)$, the severity of PTSD $(r=0.23)$ and re-experiencing symptoms as measured by the PDS $\left(r=0.20\right.$, all $\left.p^{\prime} \mathrm{s}<0.05\right)$ and dissociative symptoms $(r=0.30, p<0.01)$.

\section{Study 2: Prospective study of assault survivors}

Preliminary analyses and test of response bias

Mean picture identification rates across diagnostic groups were generally lower than in the pilot study (mean $=0.40$, s.D. $=0.20$ for assault, mean $=0.34$, S.D. $=$ 0.21 for general threat, and mean $=0.32$, s.D. $=0.21$ for neutral pictures). Identification rates for three pictures (one in each category) were consistently at floor or at ceiling across all participants (see Table 2); data for these pictures were thus excluded from further analyses. There were no differences in response bias (assault-related answers in response to general threat and neutral pictures) between the ASD and No-ASD groups $[F(1,219)=1.36, p=0.244]$. We also tested whether any of the sample characteristics that differed significantly between the ASD and No-ASD groups (see Table 1) were significantly related to PAT. There were no significant correlations (all $p^{\prime} \mathrm{s}=0.09-0.36$ ).

\section{Group differences (Hypothesis 1)}

A 2 (diagnostic group: ASD, No-ASD) $\times 3$ (picture type: assault, general threat, neutral) ANOVA showed significant main effects of picture type $[F(2,438)=7.54$, $p<0.001]$ and diagnostic group $[F(1,219)=4.66$, $p=0.032]$, and the hypothesized interaction between diagnostic group and picture type $[F(2,438)=4.42$, $p=0.013$ ]. Subsequent separate ANOVAs for the diagnostic groups showed significant effects of picture type for the ASD group $[F(2,70)=10.11, p<0.001]$ but not the No-ASD group $[F(2,368)=1.96, p=0.142]$. As expected, the ASD group identified assault-related pictures significantly better than neutral pictures $[F(1,35)=16.43, p<0.001]$ and general threat pictures $[F(1,35)=7.72, \quad p=0.009]$. The difference between general threat and neutral pictures was not significant within the ASD group $[F(1,35)=3.98, p=0.054]$. The results are shown in Table 3 .

Correlations of PAT with intrusive memories and features of PTSD (Hypothesis 2)

As expected, PAT correlated with the presence of intrusive memories in the past week $\left(r_{\mathrm{pbis}}=0.14\right.$, $p<0.05)$, with the participants' reports that these appeared 'out of the blue' $(r=0.19)$, the severity of PTSD $(r=0.18)$ and re-experiencing symptoms as measured by the PDS $(r=0.20)$, and dissociative symptoms $(r=0.21$, all $p<0.01)$.

Correlations with fear and processing during trauma (Hypothesis 3)

PAT correlated with fear $(r=0.19, p<0.01)$ and with data-driven processing during the trauma $(r=0.26$, $p<0.001$ ).

\section{Prediction of PTSD at 6 months (Hypothesis 4)}

The logistic regression analysis showed that PAT in the blurred picture task predicted a diagnosis of PTSD 
at the 6-month follow-up $\left[\chi^{2}(1, n=202)=6.131, p=\right.$ 0.013 , odds ratio (OR) $6.04,95 \%$ confidence interval (CI) 1.39-26.25, Nagelkerke $\left.R^{2}=0.045\right]$. Participants who identified more trauma-related pictures relative to neutral pictures were at greater risk of having PTSD at follow-up. Nagelkerke's $R^{2}$ indicated that this was a small effect.

\section{Discussion}

Two studies tested the hypothesis that a post-trauma processing advantage for trauma-related perceptual stimuli (PAT) contributes to intrusive re-experiencing and thus to the development of PTSD and ASD. Consistent with this hypothesis, participants with PTSD or ASD identified trauma-related stimuli in a novel blurred picture task better than neutral stimuli. By contrast, trauma survivors without PTSD or ASD showed the same pattern as non-traumatized volunteers in the pilot studies in that they identified trauma-related and neutral pictures equally well. These findings suggest that, compared to neutral stimuli, trauma survivors with post-traumatic disorders preferentially process stimuli that are reminiscent of perceptual impressions during the trauma. They extend previous reports that trauma-related words and sentences are preferentially attended to and can be more strongly primed post-trauma in people with PTSD than in those without PTSD (e.g. Foa et al. 1991; Bryant \& Harvey, 1995; Amir et al. 1996; Moradi et al. 1999; Michael et al. 2005b; Vythilingam et al. 2007). The results were not due to response bias as there were no group differences in trauma-related answers to neutral or general threat pictures. In addition, the findings were specific to trauma-related pictures as there was no processing advantage for general threat pictures in either group; both groups did not identify general threat pictures better than neutral pictures. Although a direct comparison of trauma and general threat pictures within the PTSD group in Study 1 only showed a trend for significance $(p=0.080)$, the ASD group in Study 2 identified trauma-related pictures better than general threat pictures. The overall pattern of results suggests that the processing bias for trauma-related material in ASD and PTSD assessed with this task is a perceptual bias, rather than a conceptual bias.

It is noteworthy that, in Study 2, PAT was due to a lower identification of neutral stimuli in the ASD groups compared to the No-ASD groups rather than a better identification of trauma-related stimuli. This finding may indicate that a reduced awareness of stimuli that indicate safety and normality contributes to PTSD, and to patients' impression that their current environment is threatening (Ehlers \& Clark, 2000).
The overall lower performance of participants with PTSD/ASD compared to those without PTSD/ASD in this study is consistent with general concentration deficits (e.g. Bryant \& Harvey, 1997) and relative performance deficiencies on tasks of sustained attention and initial information acquisition (Vasterling et al. 1997) found in other studies.

In both studies, PAT was related to re-experiencing symptoms and with reports that these appear 'out of the blue'. PAT may thus be one of the mechanisms involved in the involuntary triggering of memories from the trauma. The finding that PAT also predicted PTSD at the 6-month follow-up in Study 2 further supports this hypothesis. The latter extends findings that enhanced priming for trauma-related words in a word-stem completion task predicted PTSD symptoms at follow-up (Michael et al. 2005b; Ehring \& Ehlers, 2011). Together, the findings are in line with the hypothesis that a processing advantage for stimuli associated with the traumatic event contributes to PTSD (Ehlers \& Clark, 2000). Further research into the exact mechanisms is needed. PAT is likely to facilitate the detection of trauma reminders in the survivors' everyday environment. These in turn, by association, may trigger re-experiencing symptoms such as unwanted trauma memories and/or affective states such as fear or dissociation. Furthermore, patients with PTSD overestimate the likelihood of further harm (e.g. Foa et al. 1999), and the enhanced processing of trauma-related cues compared to neutral cues in their environment may contribute to these impressions. Finally, PAT may increase the chances that trauma survivors initiate dysfunctional coping responses such as avoidance, thought suppression or rumination.

In line with Hypothesis 3, PAT was associated with fear and data-driven processing during the trauma. The association with fear is consistent with memory enhancing effects of emotional arousal during encoding (e.g. McGaugh, 2000; Arntz et al. 2005; LaBar \& Cabeza, 2006), which may lead to superior recognition of emotionally arousing compared to neutral stimuli (e.g. Dolcos et al. 2005). The correlation with data-driven processing is in line with the role of perceptual processing highlighted in theories of PTSD (e.g. Brewin et al. 1996, 2010; Ehlers \& Clark, 2000) and with Roediger's (1990) transfer-appropriate processing approach.

The present studies have strengths and limitations. Among the strengths is the cross-validation of the findings in two independent samples of trauma survivors, using two trauma-specific versions of the blurred picture task. Furthermore, the prospective design of Study 2 allowed us to show that PAT is not only associated with PTSD concurrently but also predicts PTSD 6 months later. 
Among the limitations is that the task used standardized rather than individualized picture sets so that it is likely that not all of the trauma-related stimuli were equally relevant to the participants. The stimuli that people perceive during their trauma vary widely so that it is difficult to test priming for the idiosyncratic stimuli that individuals encountered during their trauma in clinical populations. Idiosyncratic stimuli may have yielded greater effect sizes (for an example of the generation of idiosyncratic picture material, see Elsesser et al. 2004).

Further studies, including experimental studies, are needed to investigate the specific cognitive processes that underlie PAT. The present studies were not designed to determine whether PAT represents an attentional or memory bias. As the present studies aimed to assess perceptual bias for stimuli that resembled those encountered during the trauma, there was no new encoding phase of the stimuli during the experiment. Although this lends greater ecological validity to the findings, the source of the processing advantage remains to be determined. If PAT reflects a memory bias, it may be due to enhanced perceptual encoding during trauma, enhanced retention or facilitation of retrieval. Clinical observations would be consistent with an implicit memory effect, as patients are often not aware of the triggers of their traumatic memories and perceive them as coming 'out of the blue' (Ehlers et al. 2002). Experimental analogue studies found that volunteers who saw traumatic films or picture stories showed enhanced priming for stimuli that occurred in a traumatic context compared to those occurring in a neutral context (Arntz et al. 2005; Ehlers et al. 2006a; Michael \& Ehlers, 2007). This suggests that it is possible that the present results reflect greater visual priming for stimuli that were present during the trauma in the PTSD group.

In conclusion, the present results show that trauma survivors with ASD or PTSD show a relative processing advantage for trauma-related stimuli compared to neutral stimuli, which is linked to intrusive re-experiencing. This is in line with the clinical observation that trauma survivors with PTSD show intrusive re-experiencing of aspects of the trauma in the presence of sensory cues that match those encountered during the trauma (Ehlers et al. 2004). Further work is required to determine whether this perceptual processing advantage reflects attentional bias or a priming effect, and whether it interacts with other memory processes, such as Pavlovian conditioning and trauma memory elaboration, in contributing to intrusive memories following trauma. Future studies should also examine whether changes in PAT accompany reductions in re-experiencing symptoms, that is during successful cognitive therapy, where trauma memories become more elaborated and cuedriven retrieval of involuntary memories typically decreases (Ehlers et al. 2005). There is some evidence from analogue studies that processing of the traumatic experience may reduce both perceptual processing advantages and re-experiencing (Michael \& Ehlers, 2007; Ehlers et al. 2010).

\section{Acknowledgements}

The studies were supported by the Wellcome Trust (grants 069777 and 066015) and the Psychiatry Research Trust. We thank Dr E. Glucksman and the staff of King's College Hospital's Emergency Department for their collaboration, and I. Böllinghaus, S. Frank, E. Briddon, A. Weidmann, I. Sengstock, J. Hissbach, J. Baumeister and S. Spengler for their help. B. Kleim is now affiliated with the University of Zurich, Switzerland, and T. Ehring with the University of Amsterdam, The Netherlands.

\section{Declaration of Interest}

None.

\section{References}

Amir N, Leiner AS, Bomyea J (2010). Implicit memory and posttraumatic stress symptoms. Cognitive Therapy and Research 34, 49-58.

Amir N, McNally RJ, Wiegartz PS (1996). Implicit memory bias for threat in posttraumatic stress disorder. Cognitive Therapy and Research 20, 625-635.

Arntz A, de Groot C, Kindt M (2005). Emotional memory is perceptual. Journal of Behavior Therapy and Experimental Psychiatry 36, 19-34.

Brewin CR, Dalgleish T, Joseph S (1996). A dual representation theory of posttraumatic stress disorder. Psychological Review 103, 670-686.

Brewin CR, Gregory JD, Lipton M, Burgess N (2010). Intrusive images in psychological disorders: clinical characteristics, neural mechanisms, and treatment implications. Psychological Review 110, 210-232.

Bryant RA, Harvey AG (1995). Processing threatening information in posttraumatic stress disorder. Journal of Abnormal Psychology 104, 537-541.

Bryant RA, Harvey AG (1997). Attentional bias in posttraumatic stress disorder. Journal of Traumatic Stress 10, 635-644.

Bryant RA, Harvey AG (2000). Acute Stress Disorder: A Handbook of Theory, Assessment, and Treatment. American Psychological Association: Washington, DC.

Buckley TC, Blanchard EB, Neill WT (2000). Information processing and PTSD: a review of the empirical literature. Clinical Psychology Review 8, 1041-1065.

Constans JI (2005). Information-processing biases in PTSD. In Neuropsychology of PTSD: Biological, Cognitive and Clinical Perspectives (ed. J. J. Vasterling and C. R. Brewin), pp. 105-130. Guilford Press: New York. 
Dolcos F, LaBar KS, Cabeza R (2005). Remembering one year later: role of the amygdala and the medial temporal lobe memory system in retrieving emotional memories. Psychological Review 107, 261-288.

Ehlers A, Clark DM (2000). A cognitive model of posttraumatic stress disorder. Behaviour Research and Therapy 38, 319-345.

Ehlers A, Clark DM, Hackmann A, McManus F, Fennell M (2005). Cognitive therapy of posttraumatic stress disorder: development and evaluation. Behaviour Research and Therapy 38, 413-431.

Ehlers A, Hackmann A, Michael T (2004). Intrusive re-experiencing in post-traumatic stress disorder: phenomenology, theory, and therapy. Memory 12, 403-415.

Ehlers A, Hackmann A, Steil R, Clohessy S, Wenninger K, Winter $\mathbf{H}$ (2002). The nature of intrusive memories after trauma: the warning signal hypothesis. Behaviour Research and Therapy 40, 995-1002.

Ehlers A, Mauchnik J, Handley R (2010). Reducing unwanted trauma memories by imaginal exposure or autobiographical memory elaboration: an analogue study of memory processes. Journal of Behavior Therapy and Experimental Psychiatry. Published online: 22 December 2010. doi:10.1016/j.jbtep.2010.12.009.

Ehlers A, Michael T, Chen YP, Payne E, Shan S (2006a). Enhanced perceptual priming for neutral stimuli in a traumatic context: a pathway to intrusive memories? Memory 14, 316-328.

Ehring T, Ehlers A (2011). Enhanced priming for traumarelated words predicts posttraumatic stress disorder. Journal of Abnormal Psychology 120, 234-239.

Ehring T, Ehlers A, Glucksman E (2006b). Contribution of cognitive factors to the prediction of post-traumatic stress disorder, phobia and depression after motor vehicle accidents. Behaviour Research and Therapy 44, 1699-1716.

Elsesser K, Sartory G, Tackenberg A (2004). Attention, heart rate, and startle response during exposure to trauma-relevant pictures: a comparison of recent trauma victims and patients with posttraumatic stress disorder. Journal of Abnormal Psychology 113, 289-301.

First MB, Spitzer RL, Gibbon M, Williams JBW (1996). Structured Clinical Interview for DSM-IV Axis I Disorders. American Psychiatric Press: Washington, DC.

Foa EB, Cashman L, Jaycox L, Perry K (1997). The validation of a self-report measure of posttraumatic stress disorder: The Posttraumatic Diagnostic Scale. Psychological Assessment 9, 445-451.

Foa EB, Ehlers A, Clark DM, Tolin D, Orsillo S (1999). The Posttraumatic Cognitions Inventory (PTCI). Development and validation. Psychological Assessment 11, 303-314.

Foa EB, Feske U, Murdock TB, Kozak MJ, McCarthy PR (1991). Processing of threat-related information in rape victims. Journal of Abnormal Psychology 100, 156-162.

Foa EB, Steketee G, Rothbaum BO (1989). Behavioral/ cognitive conceptualizations of post-traumatic stress disorder. Behavior Therapy 20, 155-176.

Halligan SL, Clark DM, Ehlers A (2002). Cognitive processing, memory, and the development of PTSD symptoms: two experimental analogue studies. Journal of Behavior Therapy and Experimental Psychiatry 33, 73-89.
Halligan SL, Michael T, Clark DM, Ehlers A (2003). Posttraumatic stress disorder following assault: the role of cognitive processing, trauma memory, and appraisals. Journal of Consulting and Clinical Psychology 71, 419-431.

Kleim B, Ehlers A, Glucksman E (2007). Early predictors of posttraumatic stress disorder in assault survivors. Psychological Medicine 37, 1457-1467.

LaBar KS, Cabeza R (2006). Cognitive neuroscience of emotional memory. Nature 7, 54-64.

McGaugh JL (2000). Memory - a century of consolidation. Science 287, 248-251.

McNally RJ, Amir N (1996). Perceptual implicit memory for trauma-related information in post-traumatic stress disorder. Cognition and Emotion 10, 551-556.

Michael T, Ehlers A (2007). Enhanced perceptual priming for neutral stimuli occurring in a traumatic context: two experimental investigations. Behaviour Research and Therapy 45, 341-358.

Michael T, Ehlers A, Halligan SL (2005b). Enhanced priming for trauma-related material in posttraumatic stress disorder. Emotion 5, 103-112.

Michael T, Ehlers A, Halligan SL, Clark DM (2005a). Unwanted memories of assault: what intrusion characteristics are associated with PTSD? Behaviour Research and Therapy 43, 613-628.

Moradi AR, Taghavi MR, Neshat Doost HT, Yule W, Dalgleish T (1999). Performance of children and adolescents with PTSD on the Stroop colour-naming task. Psychological Medicine 29, 415-419.

Murray J, Ehlers A, Mayou RA (2002). Dissociation and post-traumatic stress disorder: two prospective studies of road traffic accident survivors. British Journal of Psychiatry 180, 363-368.

Öhman A (1993). Fear and anxiety as emotional phenomenon: clinical phenomenology, evolutionary perspectives, and information processing mechanisms. In Handbook of Emotions (ed. M. Lewis and J. M. Haviland), pp. 511-536. Guilford Press: New York.

Öhman A, Soares JF (1993). On the automatic nature of phobic fear: conditioned electrodermal responses to masked fear-relevant stimuli. Journal of Abnormal Psychology 102, 121-132.

Roediger HL (1990). Implicit memory: retention without remembering. American Psychologist 45, 1043-1056.

Schacter DL (1992). Priming and multiple memory systems: perceptual mechanisms of implicit memory. Journal of Cognitive Neuroscience 4, 244-256.

Thrasher SM, Dalgleish T, Yule W (1994). Information processing in posttraumatic stress disorder. Behaviour Research and Therapy 32, 247-254.

Vasterling JJ, Brailey K, Constans JI, Borges AH, Sutker PB (1997). Assessment of intellectual resources in Gulf War veterans: relationship to PTSD. Assessment 4, 51-59.

Vythilingam M, Blair KS, McCaffrey DM, Scaramozza M, Jones M, Nikic M, Mondillo K, Hadd K, Bonne O, Mitchell DGV, Pine DS, Charney DS, Blair PJR (2007). Biased emotional attention in post-traumatic stress disorder: a help as well as a hindrance. Psychological Medicine 37, 1445-1455. 